\title{
Türkiye'de Erken Çocukluk Döneminde Baba Çocuk İlişkisi Konusunda Hazırlanan Lisansüstü Tezlerin İncelenmesi
}

\author{
The Investigation of Graduate Thesis About Father-Child Relationship in Early \\ Childhood in Turkey
}

\author{
Dr. Ögrr. Üyesi Halil UZUN \\ Kilis 7 Aralı Üniversitesi, M.R. Eğitim Fakültesi, Temel Eğitim Bölümü, \\ Okul Öncesi Eğitimi ABD, Kilis \\ uzunhalil@gmail.com \\ Dr. Ögr. Üyesi Ahmet SIMSAR \\ Kilis 7 Aralı Üniversitesi, M.R. Eğitim Fakültesi, Temel Eğitim Bölümü, \\ Okul Öncesi Eğitimi ABD, Kilis \\ ahmetsimsar@kilis.edu.tr \\ Dr. Öğr. Üyesi Nezahat Hamiden KARACA \\ Afyon Kocatepe Üniversitesi, Eğitim Fakültesi, Temel Ĕgitim Bölümü, \\ Okul Öncesi Ĕ̈itimi ABD, Afyon \\ nhamiden@gmail.com
}

Atıf: Uzun, H., Simsar, A. ve Karaca, H. N. (2019). Türkiye'de erken çocukluk döneminde baba çocuk ilişkisi konusunda hazırlanan lisansüstü tezlerin incelenmesi. E-Kafkas Eğitim Araştırmaları Dergisi, 6(2), 1-8.

Gönderi Tarihi: 17.06 .2019
Kabul Edilme Tarihi: $27-09-2019$
DOI: $10.30900 /$ kafkasegt.578894

Özet

Çocukların sağlıklı yetişkinler olmaları, sağlıklı ilişkilerin olduğu bir aile ortamında büyümelerine bağlıdır. Çocuklar birçok beceriyi ebeveynlerini gözlemleyerek ve onlardan yardım ve destek alarak öğrenirler. Çocukların gelişiminde anneler kadar babaların katkısı da çok büyüktür. Erken çocukluk döneminde çocuklar babalarının kendilerini izlemelerinden, fikir vermelerinden, yeni şeyler öğretmelerinden, onlarla oynamaktan, kısacası babalarıyla birlikte olmaktan keyif almaktadır. Ayrıca bu dönemde babalarıyla birlikte olan çocuklar gelişimleri için gerekli olan birçok bilgiyi, beceriyi ve duygusal desteği elde etmektedir. Baba çocuk ilişkisinin hem nitelik, hem de nicelik olarak anne çocuk ilişkisinden farklıdır. Araștırmacılar, babanın özellikle erkek çocuğun erkeksi davranışları kazanması açısından önemli olduğunu ortaya koymakta ve erkek çocukların babaları ile özdeşleşerek erkek gibi davranmayı öğrendiklerini ileri sürmektedir. Bu doğrultuda baba- çocuk ilişkisinin niteliğinin çocuğun birçok alandaki gelişiminin desteklenmesi açısından önemli bir yere sahip olduğu ifade edilebilir. Dolayısıyla bu çalışmada, Türkiye'de erken çocukluk eğitimi alanında 2008-2017 yılları arasında baba-çocuk ilişkisi konusunda yapılmış lisansüstü tezlerin incelenmesi amaçlanmıştır. Araştırma içerik analizi temel alınarak gerçekleştirilmiştir. Yapılan analizler sonucunda; ilgili tarihler arasında baba-çocuk ilişkisi konusunda 15 yüksek lisans, 5 doktora tezi olmak üzere toplam 20 tane lisansüstü tez yapıldığı, tezlerde en fazla tarama modelinin benimsendiği, en fazla lisansüstü tezin 2016 yılında tamamlandığı ve en fazla tezin Gazi Üniversitesi'nde yapıldığı belirlenmiştir.

Anahtar Sözcükler: Baba eğitimi, erken çocukluk dönemi, okul öncesi eğitim, baba çocuk ilişkisi.

\begin{abstract}
Children's growing up to be healthy adults depends on their being raised in a family environment with healthy relationships. Children acquire many skills by observing their parents and receiving help and support from them. The father makes a considerable contribution to child development as much as the mother. In early childhood, children enjoy that their father watches them, gives ideas, teaches new things and plays with them; in short, they enjoy it when they spend time together. Also, children who have their father with their side in this period acquire various skills, knowledge and emotional support necessary for their development. The relationship between the father and child is different from that of the mother and child, both in quality and quantity. Researchers indicate that the father is particularly important for boys to acquire masculine behaviors, and claim that boys learn to behave like a man by identifying with their fathers. In line with this claim, it can be stated that the nature of the father-child relationship is important for supporting the child's development in many areas. Accordingly, this study aimed to analyze the master's theses on the father-child relationship written in the field of early childhood education in Turkey between 2008 and 2017. The research was based on content analysis. The analyses revealed that a total of 20 postgraduate theses ( 15 master's theses and 5 doctoral dissertations) were prepared on the father-child relationship in this period, the theses mostly used the survey model, the highest number of postgraduate theses were completed in 2016 and the highest number of theses were submitted to Gazi University.

Keywords: Father training, early childhood, preschool education, father-child relationship.
\end{abstract}




\section{GíRiş}

Sosyal bilimlerde ailenin evrensel bir tanımını yapmak oldukça güçtür. TDK Türkçe Sözlük'te (2011) aile, "evlilik ve kan bağına dayanan, karı, koca, çocuklar, kardeşler arasındaki ilişkilerin oluşturduğu toplum içindeki en küçük birlik; karı, koca ve çocuklardan oluşan topluluk; aynı soydan gelen veya aralarında akrabalık ilişkileri bulunan kimselerin tümü; birlikte oturan hısım ve yakınların tümü; eş, karı; aynı gaye üzerinde anlaşan ve birlikte çalışan kimselerin bütünü; temel niteliği bir olan dil, hayvan veya bitki topluluğu" olarak tanımlanmaktadır. Genel olarak aile, anne, baba ve çocuklardan oluşan bir birim olarak tanımlansa da, aslında bu tanım ailenin bir türü olan çekirdek aileyi ifade etmektedir. En genel tanımıyla aile, biyolojik ilişkiler sonucu insan neslinin devamını sağlayan; toplumsallaşma sürecinin ilk ortaya çıktığı; karşıllıklı ilişkilerin belirli kurallara bağlandığı; o güne dek toplumda oluşturulmuş maddi ve manevi zenginlikleri kuşaktan kuşağa aktaran; biyolojik, psikolojik, ekonomik, toplumsal, hukuksal $v b$. yönleri bulunan toplumsal bir birimdir (Sayın, 1990). Bir başka tanıma göreyse aile, genelde iki cins arasındaki ilişkileri ve neslin devamlılı̆ııı düzenleyen, standartlaştıran bir sistemdir (Aydın, 2000). Aile; üyeleri arasındaki ilişkiler yönünden grup tanımı içerisine yerleştirilebildiği gibi, sosyal hayatın ana şekillerinden biri olması bakımından topluluk ve örgüt, birliğin yürütülmesinde başvurulan sistemleştirilmiş kurallar yönünden kurum ve toplumsal hayatın içindeki temel unsurlardan biri olması yönünden de toplumsal yapının bir parçası olarak düşünülebilir (Gökçe, 1990). Aile kurumunun farklı yer ve zamanlarda farklı görünümler taşımasının nedeni, içinde bulunduğu kültürlerin farklılı̆̆ıdır. Toplumsal yapıda etkili ve egemen olan ilkelerin değişmesiyle birlikte ekonomik, siyasi, dini ve ahlaki alanlarda görülebilecek değişmeler aile kurumunun da yeniden şekillenmesine yol açar (Kurt, 2006).

Çocukların sağlıklı yetişkinler olmaları, sağlıklı ilişkilerin olduğu bir aile ortamında büyümelerine bağlıdır (Erkan ve Durmuşoğlu, 2006). Çocuğun ebeveynlerinin sevgi ve ilgisiyle yetişmesi bireyin, sosyal, duygusal gelişiminin gerçekleşmesi bakımından oldukça önemlidir (Kuzucu, 2011). Aile çocuğun gelişimsel sürecindeki doğru ve yanlışlar için güçlü bir belirleyici olup, çocuğun gelişimini ve öğrenmesini derinden etkiler (Morrison, 2006). Aile, hem kalıtımla aktarılan özellikler hem de doğumdan itibaren çocuğa en yakın kişiler olarak çevresel etkenleri sağlayarak kişiliğin oluşmasında önemli rol oynar Ailesi tarafından sevgi, saygı, hoşgörü ve anlayış gören çocukların ruh sağlıklarının da olumlu yönde geliştiği görülmektedir. Olumlu ruh sağlı̆ı̆ içerisinde olan çocuklar kendisi ve yaşamıyla barışık, kendisini ve etrafındaki bireyleri seven, özgüven sahibi bir insan olarak yetişkin yaşamına uyum sağlar (Yenilmez, 2012). Aile çocukların gelecek yaşantısını önemli ölçüde etkilediğinden, anne babaların çocuk gelişimi ve eğitimi konusunda eğitilmeleri, çocukların daha iyi yetişmelerinde önemli rol oynar (Kaya, 2002). Bu doğrultuda anne baba eğitim programları sayesinde, çocukta daha yüksek kalitede öğrenme sağlanabilir (Morrison, 2006). Günümüzde ailelerin eğitim sürecine dahil edilmediği bir eğitim ile istenen amaca ulaşmanın çok zor olduğu bilinmektedir. Bu nedenle son yıllarda aile eğitimine verilen önem gittikçe artmaktadır (Can-Toprakçı, 2006; Diler Sönmez, 2008; Varol, 2005). Bununla birlikte psikoloji sosyal bir bilim olarak 20. yüzyıl boyunca gelişirken aile üzerindeki çalışmaların anne-çocuk üzerine yoğunlaştığı, baba-çocuk ilişkisinin uzunca bir dönem ihmal edildiği göze çarpmaktadır (Coltrane, 1988; Evans, 1996).

İnsanlar kadına ve erkeğe ilişkin rolleri betimlemeleri istendiğinde, kadınlar ve erkekler için farklı tanımlama yaparlar. Geleneksel babalık rolünde baba, evin geçimini sağlar, çocuğuna disiplin uygular ve nadiren çocuğuyla oyun oynar (Feldman, Nash ve Aschenbrenner, 1983). Bu babalar için çocuk bakımı, parasal destek sağlamak ve disiplin uygulamakla sınılıdır. Ailelerini ekonomik olarak destekledikleri için sorumluluklarını yerine getirdiklerini düşünürler (Barnett ve Baruch, 1988). Dünyada ve Türkiye'de yapılan birçok araştırma çocuğun eğitiminde annenin olduğu kadar babanın da önemli olduğunu ortaya koymuştur (Çağdaş, 2008; Öz, 2005; Riley $v d$., 2000; Segrin ve Flora, 2005; Tezel-Şahin, 1998). Özellikle son 30-35 y1l öncesine değin çocuğun gelişiminde babanın varlığı ve etkisi hep dolaylı olarak incelenmiş, dikkat hep anne çocuk ilişkisine yoğunlaşmışıı. 1980'li yılların ilk yarısından itibaren, babanın çocuk gelişimi ve aile yaşantısındaki etkileri üzerine yapılan araştırmalarda artış gözlenmeye başlanmıştır. Lamb'ın ortaya koyduğu Baba Katılımı Tipolojisi, babaların çocuğun gelişimi üzerindeki etkilerini araştırmayı amaçlayan çalışmalara önemli bir teorik altyapı oluşturmuştur. Lamb, baba katılımının üç önemli boyutunu belirtmiştir. Bunlardan birincisi, babalarla çocukların birlikte zaman geçirmesini ifade eden etkileşim; ikincisi, babalar ve çocukların birlikte herhangi bir etkinlik gerçekleştirmese bile, duygusal ve fiziksel yakınlık içerisinde olması ve babanın çocuğun önceliklerine zaman ayırmasını ifade eden ulaşılabilirlik; üçüncüsü ise çocuğun mutluluğu ve sağlıklı gelişimi için babanın sorumluluk üstlenmesi olarak ortaya konmuştur (Ho ve Lamb, 1987; Koçak, 2004). Babalar için hazırlanmış programların etkileri incelendiğinde, çocukların yetiştirilmesinde babaların olumlu etkilerinin olduğu, bu programlara katılan babaların çocukları ile olan ilişkilerinde olumlu gelişmeler olduğu ve kendi babalarının onlara gösterdiği ilgiden daha fazlasını çocukları için gösterme konusunda istekli oldukları belirlenmiştir (AÇEV, 2017; Cowan ve Bornstein, 1988; McBride ve McBride, 1990, Uzun 2016).

Babaların aile içinde katılım sağlamalarının doğrudan ya da dolaylı olarak çocukların üzerinde etkisinin olabileceği saptanmış, özellikle de çocukların ekonomik, fiziksel ve psikolojik iyi oluş hallerine yönelik etkisi giderek farkındalık kazanılan bir konu haline gelmiştir (Day ve Lamb, 2004). Erken çocukluk döneminde çocukların gelişimi açısından bu kadar önemli olan baba çocuk ilişkisinin çocuklar üzerindeki etkilerinin 
araştırıldığı çalışmaların incelenmesi, bu alanda ülkemizdeki bilimsel gelişmeleri ortaya koyması ve özellikle 21. yüzyılda değişen babalık rolünün toplumda nasıl gerçekleştiğinin belirlenmesi ve etkileşimci, katılımcı ve sorumluluk sahibi babalığın önemini ortaya koyması açısından önemlidir. Bu doğrultuda bu çalışmada Türkiye'de erken çocukluk döneminde baba çocuk ilişkisi konusunda yapılmış lisansüstü eğitim tezlerinin incelenmesi amaçlanmıştır.

\section{Araştırmanın Modeli}

\section{YÖNTEM}

Araştırma, Türkiye'de erken çocukluk döneminde baba-çocuk ilişkisi konusunda yapılmış lisansüstü eğitim tezlerinin tematik dağılımlarını ortaya koymak amacıyla içerik analizi temel alınarak gerçekleştirilmiştir. İçerik analizi, birbirlerine benzeyen verileri belirli kavramlar ve temalar çerçevesinde bir araya getirerek okuyucunun anlayacağı biçime dönüştürmesi nedeniyle tercih edilmiştir (Bauer, 2003; Çalık ve Sözbilir, 2014; Fraenkel ve Wallen, 2000; Yıldırım ve Şimşek, 2005).

\section{Evren ve Örneklem}

Araștırmanın evrenini, YÖK Yayın Dokümantasyon Daire Başkanlığı tarafından arşivlenen, gelișmiş tarama bölümünde baba kelimesi yazılarak filtrelenen 548 lisansüstü tez oluşturmaktadır. Araştırmanın örneklemi ise erken çocukluk döneminde baba-çocuk ilişkisi konusunda, 2008-2017 yılları arasında yapılmış 15 yüksek lisans ve 5 doktora tezi olmak üzere toplam 20 tezden oluşmuştur. İncelenecek olan tezler belirlenirken Yüksek Öğretim Kurumu Ulusal Tez Merkezi internet sitesinin gelişmiş tarama sekmesinde tez adları, baba, baba-çocuk, baba ve çocuk ilişkisi, aile ilişkileri anahtar kelimeleri kullanılarak taranmıştır. Ayrıca aynı sitenin detaylı tarama sekmesinde Okul Öncesi Öğretmenliği Anabilim Dalı, Okul Öncesi Eğitimi Ana Bilim Dalı, Çocuk Gelişimi Ana Bilim Dalı, Çocuk Gelişimi ve Ev Yönetimi Eğitimi Ana Bilim Dalı'nda yayınlanmış tezler tek tek incelerek babaçocuk ilişkisi ile ilgili olan tezler çalışmaya dâhil edilmiştir. Araştırmanın evreni dikkate alındığında erken çocukluk döneminde baba-çocuk ilişkisi konusunda yapılan lisansüstü tezlerin \% 3,65 olduğu belirlenmiştir. Alan yazın taraması sonucu ulaşılan çalışmaların araştırmaya dâhil edilmesinde, (a) çalışmanın Türkiye'de yapılmış olması, (b) yüksek lisans ve doktora tez çalışması olarak tamamlanmış olması, (c) çalışma grubunun erken çocukluk dönemindeki çocukları, aileleri veya öğretmenlerinden oluşması ölçütleri dikkate alınmıştır.

\section{Verilerin Toplanması ve Analizi}

Araştırmada ilk olarak Yüksek Öğretim Kurulu Başkanlığı Ulusal Tez Merkezi veritabanından değerlendirmeye alınan lisansüstü tezler pdf (portable document file) formatında bilgisayar ortamına aktarılmıştır ve veri toplama yöntemi olarak doküman analizi kullanılmıştır. Doküman incelemesi araştırılması amaçlanan olgu ya da olgular hakkında bilgi içeren yazılı materyallerin analizini kapsar (Yıldırım ve Şimşek, 2011). Bu doğrultuda araştırma örneklemini oluşturan yüksek lisans ve doktora tezleri yıl, kullanılan yöntem, yapıldıkları üniversite, bölge ve çocukların özel gereksinimli olup olmamalarına göre ayrılarak çözümlenmiş, araştırma sonuçları hakkında bilgi verilmiş ve sonuçlar doğrultusunda önerilerde bulunulmuştur.

\section{BULGULAR}

Çalışmada Türkiye'de erken çocukluk döneminde yapılmış lisansüstü eğitim tezlerinin incelenmesi amaçlanmıştır. Bu amaç doğrultusunda yapılan analizler tablolar hâlinde sunulmuştur.

Tablo 1.

Örnekleme Dâhil Edilen Yüksek Lisans ve Doktora Tezlerinin Yıllara Göre Dă̆ılımı

\begin{tabular}{ccc}
\hline Y1llar & Yüksek Lisans & Doktora \\
\hline 2008 & 1 & 1 \\
2009 & 1 & - \\
2010 & 3 & - \\
2012 & 1 & - \\
2013 & 2 & - \\
2014 & 2 & - \\
2015 & 1 & 1 \\
2016 & 2 & 2 \\
2017 & 2 & 1 \\
\hline Toplam & 15 & 5 \\
\hline
\end{tabular}

Tablo 1'e bakıldığında örnekleme dâhil edilen lisansüstü tezlerin y1llara göre dağılımı görülmektedir. Bu duruma göre Türkiye'de erken çocukluk döneminde baba konusunda an az 2009 (n=1) ve 2012 yılında ( $n=1$ ), en çok ise 2016 yılında lisansüstü tezin yapıldığı tespit edilmiştir. 
Tablo 2.

Örnekleme dâhil edilen lisansüstü tezlerde kullanılan yöntemlerin dă̆llımı

\begin{tabular}{lll}
\hline Kullanılan Yöntem/Model & $\mathrm{f}$ & $\%$ \\
\hline Tarama Modeli & 8 & 40 \\
Deneysel Yöntem & 6 & 30 \\
Gözlem & 3 & 15 \\
Karma Yöntem & 3 & 15 \\
\hline Toplam & 20 & 100 \\
\hline
\end{tabular}

Tablo 2'ye göre, erken çocukluk döneminde baba konusunda yapılan tezlerde en çok kullanılan yöntem/modelin "tarama modeli" olduğu $(\mathrm{n}=8, \% 40)$ görülmektedir. Bununla birlikte tezlerde en az kullanılan yöntem/modelin gözlem $(n=3, \% 15)$ ve karma yöntem $(n=3, \% 15)$ olduğu görülmektedir.

Tablo 3.

Örnekleme dâhil edilen lisansüstü ve doktora tezlerin yapıldıkları üniversitelere göre dă̆llımı

\begin{tabular}{lcc}
\hline Üniversite & $\mathrm{f}$ & $\%$ \\
\hline Gazi Üniversitesi & 7 & 35 \\
Ankara Üniversitesi & 3 & 15 \\
Selçuk Üniversitesi & 2 & 10 \\
İstanbul Üniversitesi & 2 & 10 \\
ODTÜ & 1 & 5 \\
Dokuz Eylül Üniversitesi & 1 & 5 \\
Okan Üniversitesi & 1 & 5 \\
Pamukkale Üniversitesi & 1 & 5 \\
Anadolu Üniversitesi & 1 & 5 \\
Abant İzzet Baysal Üniversitesi & 1 & 5 \\
\hline Toplam & 20 & 100 \\
\hline
\end{tabular}

Tablo 3 incelendiğinde, Gazi Üniversitesi’nde yapılan lisansüstü tezlerinin sayısının (n=7, \%35) diğer üniversitelere göre oldukça fazla olduğu, altı üniversitede ise erken çocukluk döneminde baba çocuk ilişkisi konusunda sadece bir tez yürütüldüğü belirlenmiştir.

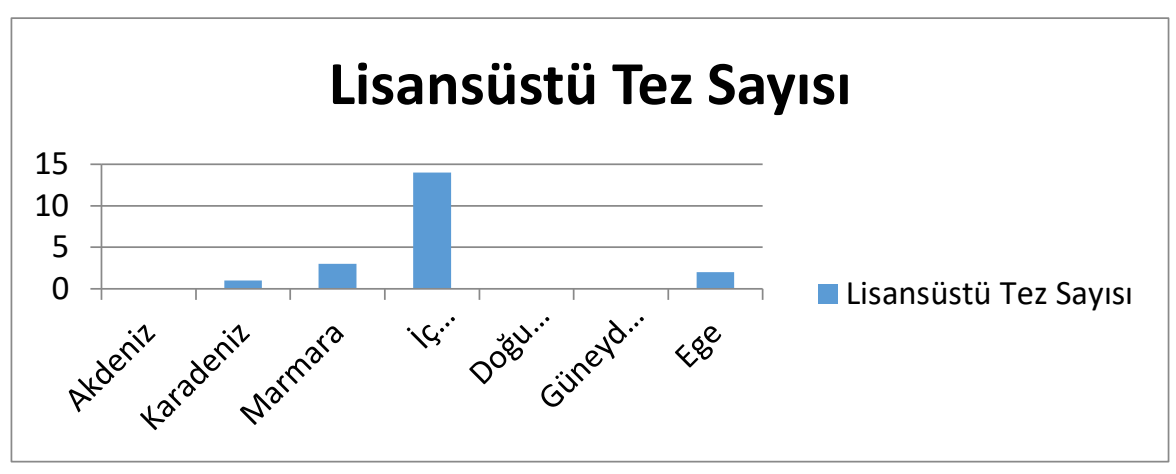

Şekil 1.

Örnekleme dâhil edilen lisansüstü ve doktora tezlerin bölgelere göre dăğlımı

Erken çocukluk döneminde baba çocuk ilişkisini konu edinen lisansüstü tezlerin bölgelere göre dağılımına bakıldığında, tezlerin büyük çoğunluğunun (n=14) İç Anadolu Bölgesinde, en az sayıda tezin ise Karadeniz Bölgesi’nde yapıldığı görülmektedir. Akdeniz, Doğu Anadolu ve Güneydoğu Anadolu Bölgesi'nde ise baba çocuk ilişkisi konusunda hiç tez yapılmadığı belirlenmiştir.

Tablo 4

Araştırmaya dâhil edilen lisansüstü tezlerin babaların normal gelişim gösteren ya da özel eğitime ihtiyaç duyan çocuklarıyla ilişkileri kapsamında değerlendirilmesi

\begin{tabular}{lll}
\hline Lisansüstü tezin kapsamı & $\mathrm{f}$ & $\%$ \\
\hline Normal gelişim gösteren çocuklar & 18 & 90 \\
Özel gereksinimli çocuklar & 2 & 10 \\
\hline Toplam & 20 & 100 \\
\hline
\end{tabular}


Tablo 4'te örneklemde yer alan lisansüstü tezlerde babaların çocuklarıyla ilişkilerinde çocuğun özel gereksinimli olma ya da olmama durumu kapsamında elde edilen veriler sunulmuştur. Bu duruma göre, hazırlanan lisansüstü tezlerin büyük bir çoğunluğunda $(\mathrm{n}=18, \% 90)$ babaların normal gelişim gösteren çocuklarla ilişkileri incelenmiş, çok azında ise $(n=2, \% 10)$ özel gereksinimli çocuklar ve babaları arasındaki ilişki incelenmiştir.

\section{SONUÇ VE ÖNERILER}

Erken çocukluk döneminde baba çocuk ilişkisi konusunda 2008-2017 yılları arasında yapılan çalışmaların incelenmesi sonucunda bu yıllar arasında 15 yüksek lisans ve 5 doktora tezi olmak üzere toplam 20 tane lisansüstü tez yapıldığı belirlenmiştir. Günümüzde babanın aile hayatındaki yeri ve çocuk için önemi dikkate alındığında bu sayının alanın gelişimi açısından yeterli olmadığı, artırılması gerektiği düşünülmektedir. Araştırma sonucunda tezlerde en fazla; tarama modelinin benimsendiği $(n=8)$, en fazla Lisansüstü tezin 2016 yılında tamamlandığ $(n=4)$, en fazla tezin Gazi Üniversitesi'nde $(n=7)$ ve İç Anadolu Bölgesi'ndeki üniversitelerde ( $n=14)$ yapıldığ 1 belirlenmiştir. Bunun nedeni erken çocukluk eğitimi alanında lisansüstü programların ilk olarak Ankara'da bulunan köklü üniversitelerde açılmış olması olabilir.

Çocuğun büyüme ve gelişiminde, özellikle erken çocukluk döneminde, anne baba ve çocuk arasındaki etkileşimin önemi uzun zamandır bilinmektedir. Bebekliğin ilk döneminden itibaren anne-baba-çocuk arasındaki iletişim ve etkileşimin kalitesi bebeğin yetişkinlere karşı güven duygusu geliştirmesini önemli düzeyde etkilemektedir. Bu nedenle anne babanın çocuklarına karşı geliştirdikleri sağlıklı iletişim ve etkileşim sayesinde birbirlerine olumlu yönde güven duygusu geliştirmelerini sağlamaktadır (Onur, 2001). Ayrıca Adler yaşamın ilk yıllarındaki çocuğa en yakın olan ebeveynlerin ilişkilerinin, bireyin kişilik özelliklerinin belirlenmesinde büyük önem taşıdığını belirtmiştir (Adler, 2005). Yapılan araştırmalara göre anne-baba çocuklarının büyüme, gelişim ve eğitimleri ile ilgili alınan eğitimlerin ebeveynlerin çocuklarıyla olan ilişkilerine olumlu yönde etki ettiği ortaya çıkmıştır (Pehrson ve Robinson, 1990; Özel ve Zelyurt, 2016). Ancak çocuk bakımı ve eğitimi denildiğinde ilk akla gelen kişi annedir. AÇEV 2017 yılında yapmış olduğu araştırma sonucunda araştırmaya katılan babaların büyük çoğunluğunun (\%91.0) çocuk bakımında birincil sorumluluğun annede olduğunu düşündüklerini belirtmiştir. Fakat 21. yüz yıldaki sosyal ve ekonomik gelişmeler sonucunda aile içindeki anne ve babanın rollerinde değişiklik olmasına neden olmuştur. Kadının iş hayatındaki yerinin artması, bebeğin doğumundan kısa bir süre sonra annenin çalışma hayatına geri dönmesi babayı çocuğun yaşamında önemli bir konuma getirmiştir (Ekşi, 1990). Ev işleri ve çocuk bakım konusunda sadece kadın veya anneler yerine eşler/babalarda görevleri üstlenmeye, dolayısı ile kadın erkek eşitliği algısı toplumlarda yaygınlaşmaya başlamıştır (Coltrane,1995). Buradan hareketle çocuk bakımında anne ve baba rollerine geleneksel bakış açısından sıyrılarak yeniden tanımlanması gerekliliği ortaya çıkmıştır.

Bununla birlikte, babanın çocukla ilişki biçiminin anneye göre farklı olduğu ve babanın toplum ve aile içinde farklı roller üstlenmesi gibi nedenlerden dolayı baba çocuk ilişkisinin anne çocuk ilişkisinden bazı farklılıklar gösterdiği de ifade edilmektedir. Çocuğun yaşamının ilk dönemlerinde babanın davranışlarının niteliği, daha sonraki dönemde çocuğun zihinsel işlevlerini etkilemektedir. Babanın bakım, beslenme, oyun vb. konulara ilgisi ile çocuğun zeka gelişimi arasında olumlu yönde bir ilişki olduğu, çocuğun cinsel ve kişilik gelişiminde babanın büyük rol oynadığı belirtilmektedir (Bronstein ve Zlotnik, 2008; Çağdaş, 2008; Güler vd., 2010; Güngörmüş-Özkardeş, 2011; Ortiz, Stile ve Brown, 1999; Swick ve Manning, 1983; Tezel-Şahin ve Özyürek, 2010; Uzun, 2016, Yavuzer, 2011). Bundan dolayı, babanın çocuğun gelişimindeki rolü anneninki kadar önem arz etmektedir. Öyleki baba-çocuk ilişkisi üzerine daha fazla araştırmalar yapılarak, bu ilişkinin çocuğun sosyalduygusal, bilişsel, fiziksel ve dil gelişimi gibi farklı gelişim alanlarına etkisi incelenebilir. Bu araştırmalar günümüz baba rolünün yeniden şekillenmesine ve tanımlanmasına da yardımcı olacaktır. Bu araştırmadan edinilen sonuçlara göre, bilim insanları lisansüstü öğrencilerini baba çocuk ilişkisi konusunda çalışmaya yönlendirilebilir. Bu araştırmada sadece Türkiye'de gerçekleştirilen lisansüstü tezler ele alınmıştır, araştırmacılar EBSCOhost, ULAKBIM, ASOS indeks, YÖK Tez ve Scholar Google (Google Akademik) gibi indeksleri tarayarak ulusal ve uluslararası araştırmaları analiz ederek yeni çalışmalar yürütebilir. Bunula birlikte, yurt içi ve yurt dışında erken çocukluk döneminde baba çocuk ilişkisi konusunda yapılmış çalışmaların paylaşılması açısından ülkemizde ulusal ve uluslararası kongreler düzenlenebilir. Ayrıca erken çocukluk döneminde görev yapan öğretmenlere baba eğitimi ve baba katılım etkinlikleri konusunda hizmet içi eğitim verilebilir.

\section{KAYNAKCA}

AÇEV (2017). Türkiye'de ilgili babalık ve belirleyicileri özet araştırma raporu. İstanbul, Taymaz Matbaacılık. Adler, A. (2005). Çocuk eğitimi. Çev. Kamuran Şipal; 3.Baskı, İstanbul:Cem Yayınevi.

Aydın, M. (2000). Kurumlar Sosyolojisi, Ankara: Vadi Yayınları.

Bauer, M. W. (2003). Classical content analysis: A review. In M. W. Bauer \& G. Gaskell (Eds.), Qualitative researching with text, image and sound (pp. 131-151). London: Sage.

Barnett, R. C. and Baruch, G. K. (1987). Determinants of father's participation in family work. Journal of Marriage and the Family, 49, 29-40.

Çalık, M., ve Sözbilir, M. (2014). İçerik analizinin parametreleri. Eğitim ve Bilim, 39(174). 
Büyüköztürk, S., Kılıç Çakmak, E., Akgün,O.E., Karadeniz,S. ve Demirel, F. (2012). Bilimsel araştırma yöntemleri. Ankara: Pegem A Yayıncilık.

Bronstein, M.H. and Zlotnik, D. 2008. Parenting styles and their effects: Infant and early childhood development. M. M. Haith and J.B.Benson (ed.), 496-509, Oxford:Elsevier.

Can Toprakçı, N. (2006). Kurumda eğitim alan zihinsel engelli öğrencilerin annelerine genişletilmiş aile eğitim programının uygulanmasının öğrencilerin matematik ders amaçlarını edinmelerinde, sürdürme ve genellemelerine etkisi. Yayınlanmamış Yüksek Lisans Tezi, Gazi Üniversitesi, Ankara.

Çağdaş, A. (2008). Anne-baba-çocuk iletişimi. Ankara: Kök Yayıncılık.

Cowan, C.P. and Bronstein, P. (1988) Father's roles in the family, implications for research. New York: A WileyInterscience publication.

Coltrane, S. (1988). Father-child relationships and status of women. A cross-cultural study. American Journal of Sociology, 93(5), 1060-1095.

Coltrane, S. (1995). The future of fatherhood: Social, demographic and economic influence on men's family involvement. (Ed: W. Marsiglio, Fatherhood contemporary theory, research and social policy. California Sage:Thousand Oaks.

Day, R. D. and Lamb, M. E. (2004). Conceptualizing and measuring father involvement: pathways, problems, and progress. R. D. Day. and M. E. Lamb, (Eds.), In Conceptualizing and measuring father involvement (pp. 1-15), New Jersey: Lawrence Erlbaum Associates.

Diler Sönmez, N. (2008). Eve dayalı gündüz tuvalet kontrolü aile eğitimi programının anneler ve zihinsel engelli çocuklarında beklenen davranış değişikliklerini gerçekleştirmede etkisi. Yayınlanmamış Doktora Tezi, Gazi Üniversitesi, Ankara.

Ekşi, A. (1990). Çocuk, genç, ve anababalar. İstanbul: Bilgi yayınevi.

Erkan, S. ve Durmuşoğlu, M.C. (2006). Anne eğitimi programının annenin çocuk yetiştirme tutumlarına etkisinin incelenmesi. Avrupa Birliği Sürecinde Okul Öncesi Eğitimin Geleceği Sempozyumu, İstanbul:Ya-Pa Yayın Pazarlama, s. 349-360.

Evans, C. (1996). Düşük sosyo-ekonomik örneklemli Türk babaların rollerine yönelik tutumlarl ve katılımları. Yayınlanmamış Yüksek Lisans Tezi, Boğaziçi Üniversitesi, İstanbul.

Feldman, S.S., Nash, S.C. and Aschenbrenner, B. C. (1983). Antecedents of fathering. Child Development, 54, 1628-1363.

Fraenkel, J. R. and Wallen, N. (2000). How to design and evaluate research in education (4 ${ }^{\text {th }}$ ed.). NY: McGrawHill.

Gökçe, B. (1990) Aile ve aile tipleri üzerine bir inceleme: Aile yazıları ı-temel kavramlar, yapı ve tarihi süreç. Ankara: T.C. Başbakanlık Aile Araştırma Kurumu Başkanlığı Yayınları, Bilim Serisi 5/1, s. 205-223

Güler, T., Ertürk, H. G., Özyürek, A., Tezel Şahin, F., Kıldan, A. O., Cavkaytar, A., Ünlüer, E., Aydoğan, Y., Kalkan, E. ve Şen, M. (2010). Anne baba eğitimi. Tülin Güler (ed.). Ankara: Pegem Akademi.

Güngörmüş Özkardeş, O. (2011), Ana-baba okulu: baba-çocuk ilişkisi. (15. Basım) Haluk Yavuzer (ed.), İstanbul: Remzi Kitapevi.

Ho, Y. F. and Lamb, M. E. (1987). The father's role: Cross-cultural perspective. New Jersey: Lawrence Erlbaum. Karasar, N. (2007). Bilimsel araştırma yöntemi, Ankara: Nobel Yayın Dağıtım.

Kaya, Ö. M. (2002). Okul öncesi ĕgitim kurumlarında uygulanan programlara ailelerin ilgi ve katılımları ile okul öncesi eğitim kurumlarının aile eğitimine katkısı konusunda anne-baba görüşleri. Yayınlamamış Yüksek Lisans Tezi, Anadolu Üniversitesi Eğitim Bilimleri Enstitüsü, Eskișehir.

Koçak,A.A.(2004).Babadestekprogramıdeğerlendirmeraporu.http://www.acev.org/kaynaklarimiz/arastirmalarim iz-ve-yayinlarimiz. Adresinden 23.07.2017 tarihinde erişilmiştir.

Kurt, A. (2006). Dünden bugüne Türk ailesi: Dünden bugüne Türkiye' nin toplumsal yaplş. Ed. Zincirkıran M, Ankara: Nova Basın Yayın.

Kuzucu, Y. (2011). Değişen babalık rolü ve çocuk gelişimine etkisi. Türk Psikolojik Danışma ve Rehberlik Dergisi, 4(35), 79-91.

Mc Bride, B.A. \& Mc Bride, R.J. (1990). Rethinking the role of fathers: Meeting their needs through support programs. Illinois Teacher. 33; 89-93.

Morrison, G. S. (2006). Fundamentals of early childhood education. New Jersey: Pearson Prentice Hall.

Onur, B. (2001). Çocuk ve ergen gelişimi. Ankara: İmge Kitabevi Yayınları.

Ortiz, R., Stile, S. and Brown, C. (1999). Early literacy activities of fathers: Reading and writing with young children. Young Children, 54(5); 16-18.

Öz, İ. (2005). Çocuk ve iletişim, Ankara: KÖK Yayıncılık.

Özel, E. ve Zelyurt, H. (2016). Anne baba eğitiminin aile çocuk ilişkilerine etkisi. Sosyal Politika Çalışmaları Dergisi, (36).

Pehrson, K. L. and Robinson, C. C. (1990). Parent education: Does it make a diference? Child Study Journal, 20(4), 221-236. 
Riley, R. W., Peterson, T. K., Moreno, M. G., and Goode, W. W. (2000). Strengthening participation of fathers in children's learning and development. Fathers mather involving fathers in children's learning. A kit for educators and other professionals. ED, 442, 580. Involving fathers in children's learning, A kit for educators and other professionals, USA.

Sayın, Ö. (1990). Aile sosyolojisi - ailenin toplumdaki yeri. İzmir: Ege Üniversitesi Edebiyat Fakültesi Yayınları No: 57.

Segrin C. and Flora, J. (2005). Family communication, London: Lawrence Erlbaum Associates, Publishers.

Swick, K.J. and Manning, M.L. (1983). Father involvement in home and school settings. 60 (2); 128-132.

Tezel Şahin F. (1998). Destekleyici eğitim programlarının 5-6 yaş grubunda çocuğu olan babalar üzerindeki etkilerinin incelenmesi. Yayınlamamış Doktora Tezi, Hacettepe Üniversitesi Sağlık Bilimleri Enstitüsü, Ankara.

Tezel Şahin, F. ve Özyürek, A. 2010. Anne baba eğitimi ve okul öncesinde aile katılımı. İstanbul: Morpa Kültür Yayınlar1.

Türk Dil Kurumu (2011). Türkçe sözlük. Ankara: Türk Dil Kurumu Yayınları.

Uzun H. (2016). Baba eğitim programının baba-çocuk ilişkisine ve anaokuluna devam eden çocukların sosyal becerilerine etkisinin incelenmesi, Yayınlamamış Doktora Tezi, Ankara Üniversitesi, Fen Bilimleri Enstitüsü, Ankara.

Varol N. (2005). Aile eğitimi, (4. Basım). Ankara: Kök Yayıncılık.

Yavuzer, H. 2011. Ana baba okulu (15. Basım). İstanbul: Remzi Kitabevi.

Yenilmez, Ç. (2012). Aile ilişkileri, Aile yapısı ve ilişkileri (s. 20-41). Eskişehir: Anadolu Üniversitesi.

Yıldırım, A. ve Şimşek, H. (2011). Sosyal bilimlerde nitel araştırma yöntemleri. Ankara: Seçkin yayınevi 


\title{
The Investigation of Graduate Thesis About Father-Child Relationship In Early Childhood In Turkey
}

\author{
Dr. Ögr. Üyesi Halil UZUN \\ Kilis 7 Aralık Üniversitesi, M.R. Ĕ̈itim Fakültesi, Temel Eğitim Bölümü, \\ Okul Öncesi Ë̆itimi Anabilim Dalı, Kilis \\ uzunhalil@gmail.com \\ Dr. Öğr. Üyesi Ahmet SIMSAR \\ Kilis 7 Aralık Üniversitesi, M.R. Ĕ̆itim Fakültesi, Temel Eğitim Bölümü, \\ Okul Öncesi Eğitimi Anabilim Dalı, Kilis \\ ahmetsimsar@kilis.edu.tr \\ Dr. Ögr. Üyesi Nezahat Hamiden KARACA \\ Afyon Kocatepe Üniversitesi, Eğitim Fakültesi, Temel Eğitim Bölümü, \\ Okul Öncesi Eğitimi Anabilim Dalı, Afyon \\ nhamiden@gmail.com
}

Citation: Uzun, H., Simsar, A. ve Karaca, H., N. (2019). The investigation of graduate thesis about father-child relationship in early childhood in Turkey. E-Kafkas Journal of Educational Research, 6(2), 1- 8.

\section{Extended Summary}

\section{Purpose}

The reasons for having different meanings and stating times of the family are having differences in cultural backgrounds. Changes in economic, political, religious and moral spheres impacts on the values of the family (Kurt, 2006). The fact that children can be adult in the future due to their good family background (Erkan ve Durmuşoğlu, 2006), it's important to have good parents' interactions and love with their children on child' social-emotional development (Kuzucu, 2011). Since parents have a significant impact on the future life of children, the education of parents on child development and education plays an important role in raising children better (Kaya, 2002). That's why children may learn better due to their parents' education programs (Morrison, 2006). The literature about child's education, the father has also responsibilities as much as mothers (Tezel-Şahin, 1998; Riley vd., 2000; Öz, 2005; Segrin ve Flora, 2005; Çağdaş, 2008). Especially until the last 30-35 years, the presence and influence of the father in the development of the child has always been indirectly examined, and attention has always been concentrated in the mother-child relationship. Since the first half of the 1980s, research on the effects of the father on child development and family life has started to increase and the importance of the father's place in the life of the child has been emphasized. That's why the purpose of this study was to investigate the early childhood education literature which made as graduate thesis and dissertations on Turkey.

\section{Method}

This research used descriptive study method by the revealing graduate theses about father-child relationships in Turkey. Document analyze method was used while collecting data. The population of the study was 548 graduate thesis which found by the typing $<<$ father $>>$ on the YÖK Yayın Dokümantasyon Daire Başkanlığı. The sample of the study was 20 graduate theses (15 master theses and $5 \mathrm{Ph} . \mathrm{D}$. dissertations) which were related to father-child relationships in early childhood educations during 2008-2017. Considering the populations of study, the sample of the study was $3.65 \%$ of the populations.

\section{Conclusion and Discussion}

The study results showed that there were 20 graduate theses which are related to father-child relation in early childhood during 2008-2017 (15 master theses and 5 Ph.D. dissertations). Considering the fathers' role in family and child, it is thought that there was a really low number of studies about father-child interactions. The study results showed that most of the studies used descriptive study method $(n=8)$, most of the study has been done in $2016(n=4)$, most of the studies have been finished in Gazi University ( $n=7)$, and most of the study was held in universities in The Central Anatolia Region. 